\title{
EFFECT OF HEATING RATE ON THE THERMODYNAMIC PROPERTIES OF PULVERIZED COAL
}

\author{
Semi-Annual Progress Report
}

For the Period March 24, 1998 to September 23, 1998

Ramanathan Sampath (Principal Investigator)

October 1998

Grant No. DE-FG22-96PC96224 -04

For

AAD Document Control

U.S. Department of Energy

Federal Energy Technology Center

P.O. Box 10940, MS 921-143

Pittsburgh, PA 15236-0940

By

Department of Engineering

Clark Atlanta University

Atlanta, GA 30314 


\section{DISCLAIMER}

This report was prepared as an account of work sponsored by an agency of the United States Government. Neither the United States Government nor any agency thereof, nor any of their employees, makes any warranty, express or implied, or assumes any legal liability or responsibility for the accuracy, completeness, or usefulness of any information, apparatus, product, or process disclosed, or represents that its use would not fringe privately owned rights. Reference herein to any specific commercial product, process, or service by trade name, trademark, manufacturers, or otherwise does not necessarily constitute or imply its endorsement, recommendation, or favoring by the United States Government or any agency thereof. The views and opinions of authors expressed herein do not necessarily state or reflect those of the United States Government or any agency thereof. 


\title{
EFFECT OF HEATING RATE ON THE THERMODYNAMIC PROPERTIES OF PULVERIZED COAL
}

\begin{abstract}
This semi-annual technical progress report describes work performed under DOE Grant No. DE-FG22-96PC96224 during the period March 24, 1998 to September 23, 1998 which covers the fourth six months of the project. Existing laser heating set-up at the Single Particle Laboratory, Federal Energy Technology Center, Morgantown, WV would work only in the range of $10^{4}$ to $10^{5}$ $\mathrm{K} / \mathrm{s}$. During this reporting period, appropriate changes were made to the laser heating system to heat particles in the range of $10^{4}$ to $10^{7} \mathrm{~K} / \mathrm{s}$. Also, calibration for all the components of the electrodynamic balance measurement system including single-color pyrometer and heating laser was successfully completed. Following the calibration, a large number of single coal particles were caught in the electrodynamic balance and their volume, external surface area, mass, and density were measured. The same single particles were then heated bidirectionally with a pulsed (10 ms pulse width) Nd:YAG laser beams of equal intensity. The temporal power variation in the laser pulse was monitored for use in the heat transfer analysis by an ultra-fast fiber optic uv light transmitter included in the beam path and coupled to a silicon photodiode. Measurements of changes in particle size that accompanied rapid heating was made by means of the high-speed diode array imaging system discussed in our previous reports. Dynamics of volatile evolution and particle swelling were recorded using well established time-resolved high-speed cinematography. Measurements of the radiant emissive power from the heated and cooled (when the laser is turned off) particles was made using the single-color pyrometer. The above experiments are being repeated for a significant number of coal particles for a number of heating rates in between $10^{4}-10^{7} \mathrm{~K} / \mathrm{s}$ at FETC, Morgantown. Shipment of the donated heated grid system components from our industrial partner, United Technologies Research Center (UTRC), CT to CAU was complete during this reporting period. Testing of the heated grid system components at CAU is also in progress.
\end{abstract}




\section{TABLE OF CONTENTS}

page

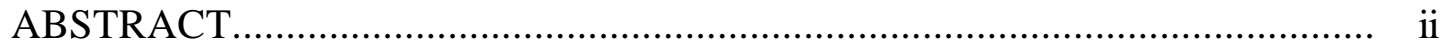

EXECUTIVE SUMMARY ..................................................................... 1

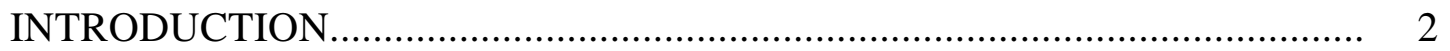

PROGRESS TO DATE ................................................................ 2

WORK PERFORMED DURING THIS PERIOD ......................................... 3

OUTCOMES TO DATE........................................................................ 5

PLANS FOR THE NEXT REPORTING PERIOD ...................................... 6

SUMMARY AND CONCLUSIONS......................................................... 6

ACKNOWLEDGMENTS................................................................. 6

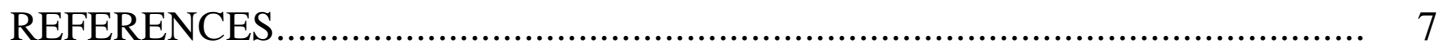




\section{EXECUTIVE SUMMARY}

In this semi-annual report, the work performed under DOE Grant No. DE-FG22-96PC96224 during the period March 24, 1998 to September 23, 1998 is described and the major accomplishments are highlighted summarizing the most important research results.

In all major coal conversion processes, coal undergoes a devolatilization stage while it is heated to the reaction temperature. The recent experimental studies of devolatilization of pulverized coal at rapid heating rates representative of coal combustors have greatly improved our general understanding of this process. But the heat transfer analysis with commonly-applied thermal properties developed from slow heating rate experiments did not predict either the early heating or the latter stages of heating. Knowledge of the role of heating rate on coal thermal properties is essential to progress in advanced coal utilization technology.

The objectives of this proposal are to understand the effect of heating rate on thermal properties of pulverized coal particles. The specific objectives are to subject coal particles into a broad range of heating rates, measure temperature histories, and develop thermal property (heat capacity and thermal conductivity) data that predict the measured temperature histories.

Experiments and modeling are being carried out to meet the project objectives. The successful accomplishment of the above goals will enhance our understanding of coal thermal properties and hence progress towards advanced combustion modeling.

During this reporting period, calibration for all the components of the electrodynamic balance measurement system including single-color pyrometer and heating laser at the Single Particle Laboratory, Federal Energy Technology Center, Morgantown, WV was successfully completed. The original set-up of the heating laser would heat particles only in the range of $10^{4}$ to $10^{5} \mathrm{~K} / \mathrm{s}$. Prior to calibration, power attenuator and the charge voltage of the heating laser system were carefully adjusted and the beam path reconfigured to heat particles in the range of $10^{4}$ to $10^{7} \mathrm{~K} / \mathrm{s}$. Following the calibration, a large number of single coal particles were caught in the electrodynamic balance and their volume, external surface area, mass, and density were measured. The same single particles were then heated bidirectionally with the heating laser and particle surface temperatures were measured using the single-color pyrometer. The temporal power variation in the laser pulse was monitored for use in the heat transfer analysis by an ultra-fast fiber optic uv light transmitter. Measurements of changes in particle size that accompanied rapid heating was made by means of the high-speed diode array imaging system. Dynamics of volatile evolution and particle swelling were recorded using time-resolved high-speed cinematography. The above experiments are being repeated at FETC, Morgantown for a significant number of coal particles with heating rates in between $10^{4}$ $10^{7} \mathrm{~K} / \mathrm{s}$. Shipment of the donated heated grid system components from UTRC to CAU was complete during this reporting period. Inspection and testing of the heated grid system components at CAU are also in progress. 


\section{INTRODUCTION}

This semi-annual technical progress report describes work performed under DOE Grant No. DE-FG22-96PC96224 during the period March 24, 1998 to September 23, 1998 which covers the fourth six months of the project.

In all major coal conversion processes, coal undergoes a devolatilization stage while it is heated to the reaction temperature. Recent experimental studies of devolatilization of pulverized coal at rapid heating rates representative of coal combustors have greatly improved our general understanding of this process [1-18]. But the heat transfer analysis with commonly-applied thermal properties developed from slow heating rate experiments did not predict either the early heating or the latter stages of heating [1-3,18-19]. Design of coal combustion and conversion processes require knowledge of thermal properties to construct an energy balance. It is accepted that there are uncertainties in the heat capacity of coal especially for the high heating rate studies [2,6]. It is also accepted that the large thermal gradients within the particle (due to thermal conductivity of coal) make prediction of the temperature difficult during the early heating in these studies [6]. However, there has been no independent study conducted to investigate the effect of heating rate on the thermal properties of coal particles. Knowledge of the role of heating rate on coal thermal properties is essential to progress in advanced coal utilization technology.

The objectives of this proposal are to understand the effect of heating rate on thermal properties of pulverized coal particles. The specific objectives are:

1) Subject coal particles into a broad range of heating rates and extract heat capacity information for high heating rate applications.

2) Also develop thermal conductivity information for coal particles subjected to rapid heating rates representative of coal combustors.

Experiments and modeling are being carried out to meet the project objectives. The successful accomplishment of the above goals will provide better understanding of coal thermal properties in high heating rate applications and hence improved combustion modeling.

\section{PROGRESS TO DATE}

Literature articles [1-45] were reviewed to understand the effect of heating rate on various parameters of a coal particle. The role of heating rate on the onset of volatile evolution, volatile yield, product composition to a lesser extent, coal type and particle size were found to be well established. As heating becomes more rapid, the onset of devolatilization shifts to much smaller time scales and to much higher surface temperatures [2,18-19]. However, the role of heating rate on coal thermal properties was not found to be well understood. Previous results clearly demonstrated that particle temperature-dependent thermal property assumptions routinely applied in coal combustion models result in large errors (up to 100 percent) in calculated temperature histories [2,18-19]. 
Remote access from CAU to the VAX/VMS system at FETC/Morgantown was established through telnet. Several modifications to the existing Single Particle Heat Transfer code were made that include option for various input and/or combinations of input for thermal properties such as constant, temperature-dependent, heating rate dependent, and time dependent values. Many sensitivity analyzes were employed to evaluate and quantify the impact of several heat transfer parameters for coal such as thermal properties and heat transfer coefficient, geometry related properties such as shape, mass, and density, and chemical properties such as devolatilization kinetic coefficients on rapid heating. This work improved the model performance of the present work, and also aided in several publications [46-50].

Approval for physical access to the Single Particle Laboratory at FETC/Morgantown from Morgantown facility was obtained. This required completion of several laboratory safety courses by CAU researchers including the PI at the Morgantown site.

Several polystyrene spheres were caught in the electrodynamic balance system at FETC/Morgantown and the operation of the associated system components such as video-based imaging systems, diode-array imaging system, dc and ac power supply, particle position control, and GE tungsten strip lamp \& lens systems for pyrometer were tested and found to be performing well. Completed calibration of several components of the balance measurement system including imaging systems and particle position control system. Also completed was the alignment and calibration of the heating laser to heat coal particles, and the single-color pyrometer to measure particle temperature histories.

Approvals from FETC/Pittsburgh, CAU, and UTRC for performing the heated grid work at Clark Atlanta University (CAU), GA, that was originally planned at United Technologies Research Center (UTRC), CT, were obtained. More recently, donation agreement for the heated grid measurement system from UTRC was obtained and the shipment of the grid components from UTRC to CAU was complete. Purchase of several instrumentation that were not available in the package from UTRC that include power supply, data acquisition interface, and spot welder was made by CAU.

\section{WORK PERFORMED DURING THIS PERIOD}

Existing laser heating set-up at the Single Particle Laboratory, Federal Energy Technology Center, Morgantown, WV would work only in the range of $10^{4}$ to $10^{5} \mathrm{~K} / \mathrm{s}$. During this reporting period, appropriate changes were made to heat particles in the range of $10^{4}$ to $10^{7} \mathrm{~K} / \mathrm{s}$. For this, power attenuator and the charge voltage of the heating laser system were carefully adjusted, beam path reconfigured and aligned, and the laser power characterized to obtain optimum spatial and temporal distribution.

Calibration for all the components of the electrodynamic balance measurement system including single-color pyrometer and heating laser was successfully completed. Following the calibration, a few coal particles were injected into the balance and by application of ac and dc potentials to the ring and endcap electrodes, a single particle that had a higher charge-to-mass ratio 
Table 1. Raw Data for the EDB Experiments March 24 - September 23, 1998

\begin{tabular}{|c|c|c|c|c|c|c|c|c|c|c|c|c|}
\hline & & Rotation & Rotation & Rotation & Rotation & Laser & Side & Side & Side & Top & Top & Top \\
\hline Part\# & $\mathrm{Cd} / \mathrm{m}$ & Area & Volume & Dp area & Dp vol & Power & Dp area & Dp \#line & Dp \#width & Dp area & Dp \#line & Dp\#width \\
\hline 1 & 49 & 26841 & 326542 & 93 & 85 & 0.63 & 85 & 84.8 & 88.4 & 77 & 93.8 & 70.8 \\
\hline 2 & 52 & 33015 & 449444 & 103 & 95 & 0.65 & 74 & 115.3 & 57.4 & 82 & 65.9 & 113.2 \\
\hline 3 & 31 & 34713 & 537058 & 105 & 101 & 0.63 & 95 & 113.6 & 84.5 & 91 & 77.8 & 103.8 \\
\hline 4 & 32 & 36345 & 543636 & 108 & 101 & 0.64 & 106 & 100.1 & 112.3 & 107 & 113.6 & 99 \\
\hline 5 & 22.5 & 47664 & 805956 & 123 & 115 & 0.64 & 123 & 164.5 & 93.9 & 99 & 105.6 & 101.5 \\
\hline 6 & 80 & 75865 & 1533570 & 155 & 143 & 0.66 & 144 & 170.1 & 142 & 130 & 126.9 & 151.5 \\
\hline 7 & 28 & 41374 & 691213 & 115 & 110 & 0.65 & 118 & 114.2 & 139 & 103 & 134.4 & 75.8 \\
\hline 8 & 35 & 31006 & 408401 & 99 & 92 & 0.65 & 102 & 159.4 & 80.4 & 82 & 79.7 & 91.6 \\
\hline 9 & 27 & 49500 & 798314 & 126 & 115 & 0.65 & 100 & 131 & 82.6 & 105 & 84.9 & 153 \\
\hline 10 & 32 & 34096 & 518157 & 104 & 100 & 0.66 & 105 & 114.9 & 91.4 & 81 & 78.4 & 95.7 \\
\hline 11 & 36 & 34933 & 515043 & 105 & 99 & 0.33 & 110 & 100.7 & 125.9 & 101 & 115.4 & 94.6 \\
\hline 12 & 29 & 40315 & 660464 & 113 & 108 & 0.33 & 125 & 135.4 & 138.2 & 96 & 134 & 80 \\
\hline 13 & 34 & 33469 & 464040 & 103 & 96 & 0.4 & 101 & 94.6 & 116.1 & 96 & 115.3 & 90.2 \\
\hline 14 & 27 & 62815 & 970536 & 141 & 123 & 0.4 & 124 & 104.7 & 165.9 & 120 & 162.3 & 94.4 \\
\hline 15 & 30 & 51816 & 828580 & 129 & 117 & 0.32 & 109 & 144.2 & 88.9 & 107 & 93.4 & 122.9 \\
\hline
\end{tabular}

was confined at the null position of the balance. Following the approach of Maloney et al. [21-23], the particle volume, external surface area, mass, and density were measured. The same particle was then heated bidirectionally with a pulsed (10 ms pulse width) Nd:YAG laser beams of equal intensity. Using the approach of Sampath [18-19], the temporal power variation in the laser pulse was monitored for use in the heat transfer analysis by an ultra-fast fiber optic uv light transmitter included in the beam path and coupled to a silicon photodiode. Measurements of changes in particle size that accompanied rapid heating was made by means of the high-speed diode array imaging system. Dynamics of volatile evolution and particle swelling was recorded using well established [2,5,18] time-resolved high-speed cinematography. Measurements of the radiant emissive power from the heated and cooled (when the laser was turned off) particles was made using the single-color pyrometer. Particle experimental temperatures was calculated from the measurements of particle size and radiant emissive power by applying the Wein approximation to Plank's law. The above experiments are being repeated for a significant number of coal particles for various heating rates in between $10^{4}-10^{7} \mathrm{~K} / \mathrm{s}$. Raw size and intensity data for 15 coal particles tested during this reporting period are presented in Table 1. Further experimentation and data reduction, and numerical analysis for the effect of thermal properties on the temperature histories are in progress.

Dr. Sampath, PI of this project, was at FETC/Morgantown in several visits during this reporting period. He was involved in the alignment and setting up of the pyrometry system. Dr. Esmail Monazam who has coauthored with the PI in a number of publications in the subject matter is working as a part-time research associate in this project and is stationed at FETC/Morgantown. Dr. Monazam is involved in the experimental activities discussed above.

Donation agreement for several components of the heated grid measurement system from UTRC was obtained during this reporting period and the shipment of the donated components from UTRC to CAU was complete. Purchase of several instrumentation that were not available in the donation package from UTRC that include power supply, data acquisition interface, and spot welder 
was made by CAU. Inspection and testing of the grid components, and their installation at CAU, and the modification and testing of the heated grid numerical code at CAU are in progress.

Joie C. Taylor, an undergraduate student in Engineering, was partially supported and trained in the subject matter.

Several theoretical analyses were conducted to improve the model performance of the present work and the results were compared with data available from our previous studies. These activities resulted in one journal publication [47], three conference presentations [46,49-50], and one symposium presentation [48] during this reporting period.

\section{OUTCOMES TO DATE}

1. Sampath, R., Monazam, E. R., Maloney, D. J., and Zondlo, J. W., Development of Improved Coal Combustion Modeling: Analysis of Coal Particle Irregularity and Thermal Properties on Temperature Predictions, Fifth Annual HBCU conference organized by FETC/DOE at Southern University and A\&M College, LA, March 1997.

2. Sampath, R., Maloney, D. J., and Monazam, E. R., Effect of Heating Rate on the Thermodynamic Properties of Pulverized Coal, Contractors Review Meeting, Fifth Annual HBCU conference organized by FETC/DOE at Southern University and A\&M College, LA, March 1997.

3. Taylor, J. C., Sampath, R., Maloney, D. J., Zondlo, J. W., and Monazam, E. R., Transport Phenomena of Irregularly-Shaped Solid Particles in an Electrodynamic Balance, Poster Paper, Fifth Annual HBCU conference organized by FETC/DOE at Southern University and A\&M College, LA, March 1997.

4. Sampath, R., Maloney, D. J., Zondlo, J. W., and Monazam, E. R., Temperature Histories for Single Coal Particles Prior to Devolatilization, Central States Technical Meeting, Combustion Institute, April 1997, Point Clear, AL.

5. Taylor, J. C., Sampath, R., and Maloney, D. J., Characterization of Small Single Particles in an Electrodynamic Balance, Annual Student Scientific Research Symposium, April 15, 1997, Clark Atlanta University, Atlanta, GA.

6. Sampath, R., Maloney, D. J., Zondlo, J. W., and Monazam, E. R., Evaluation of Errors Resulting From Nusselt Number Assumptions in Coal Combustion Modeling, Paper No. DETC97/CIE-4519, 1997 ASME Design Engineering Technical Conferences, September 14-17, 1997, Sacramento, CA.

7. Maloney, D. J., Sampath, R., and Zondlo, J. W., Heat Capacity and Thermal Conductivity Considerations for Coal Particles During the Early Stages of Rapid Heating, Combustion and Flame 116:94-104 (1999). 
8. Sampath, R., Maloney, D. J., and Zondlo, J. W., Evaluation of Thermophysical and Thermochemical Heat Requirements for Coals at Combustion Level Heat Fluxes, 27th International Symposium on Combustion, August 2-7, 1998, Boulder, CO.

9. Sampath, R., Maloney, D. J., and Proscia, W., Thermal Property Data for Coal Particles for Use in Rapid Devolatilization Models, Technology Transfer Session, Historically Black Colleges/Universities and Other Minority Institutions Annual Symposium, April 28-29, 1998, Ocean City, MD.

10. Taylor, J., Sampath, R., Maloney, D. J., and Proscia, W., Rapid Devolatilization Studies for Coal Particles in an Electrodynamic Balance and in a Heated Grid Reactor, Technology Transfer Session, Historically Black Colleges/Universities and Other Minority Institutions Annual Symposium, April 28-29, 1998, Ocean City, MD.

11. Sampath, R., Maloney, D. J., and Zondlo, J. W., Measurements of Surface Area and Volume for Irregularly-Shaped Coal Particles, Central States Technical Meeting, Combustion Institute, 31 May - 2 June, 1998, Lexington, KY.

\section{PLANS FOR THE NEXT REPORTING PERIOD}

In the near future, high-heating rate experiments will be completed at FETC, Morgantown, and heated grid work will be carried out at CAU. Following these activities, data reduction and numerical analyses will be made and the effect of heating rates on coal thermal properties evaluated.

\section{SUMMARY AND CONCLUSIONS}

The project is progressing well. Calibration activities for various instruments of the EDB measurement system, Single Particle Laboratory, FETC, Morgantown, were completed. Donation agreement for the donation of several components of the heated-grid system from UTRC, our industrial collaborator in this project, was obtained. Shipment of donated components from UTRC to CAU was complete. Calibration of the single-color pyrometer, and heating laser at the Single Particle Laboratory, FETC, Morgantown was complete. Temperature measurements on 15 coal particles subjected to very high heating rates were made during this reporting period and further experimentation to about 30 particles is in progress.

\section{ACKNOWLEDGMENTS}

The project is supported by FETC/Pittsburgh under Grant No. DE-FG22-96PC96224. Assistance provided by Dr. Daniel J. Maloney, Single Particle Laboratory, FETC/Morgantown, during this reporting period is appreciated. Technical discussions provided by Dr. Mildred B. Perry are also gratefully appreciated. 


\section{REFERENCES}

1. Fletcher, T. H., Time-resolved temperature measurements of individual coal particles during devolatilization, 1989. Combust. Sci. and Tech. 63, 89.

2. Maloney, D. J., E. R. Monazam, S. W. Woodruff, and L. O. Lawson., Measurement and analysis of temperature histories and size changes for single carbon and coal particles during the early stages of heating and devolatilization, 1991. Combustion and Flame 84: 210-220.

3. Solomon, P. R., M. A. Serio, R. M. Carangelo, and J. R. Markham., 1986. Fuel 65, 182.

4. Tichenor, D. A., Mitchell, R. E., Hencken, K. R., and Niksa, S., Simultaneous in situ measurement of the size, temperature and velocity of particles in a combustion environment, Twentieth Symposium (International) on Combustion, p. 1213, The Combustion Institute, 1985.

5. Phouc, T. X. and D. J. Maloney, Laser Pyrolysis of single coal particles in an electrodynamic balance, Twenty-Second Symposium (International) on Combustion, 1988/pp. 125-134.

6. Solomon, P. R., Serio, M. A., and E. M. Suuberg, Coal pyrolysis: experiments, kinetic rates and mechanisms, Prog. Energy Combust. Sci. 1992, Vol. 18, p. 142.

7. Niksa, S. 1986. The Distributed Energy Chain Model for Rapid Coal Devolatilization Kinetics, Part II: Transient Weight Loss Correlations, Comb. Flame, 66, 111.

8. Serio, M. A., P. R. Solomon, D. G. Hamblen, J. R. Markham, and R. A. Carangelo. Coal Pyrolysis Kinetics and Heat Transfer in Three Reactors. Twenty-first Symposium (International) on Combustion, 1986. Combustion Inst., Pittsburgh, PA, 1986, p. 153.

9. Freihaut, J. D., and W. M. Proscia. 1989. Tar Evolution in heated-grid apparatus, Energy and Fuels, 3, 625 .

10. Freihaut, J. D., Zabielski, M. F. and D. J. Seery. A parametric investigation of tar release in coal devolatilization, Nineteenth Symposium (International) on Combustion/The Combustion Institute, 1982/pp. 1159-1167.

11. Fletcher, T. H. Time-resolved particle temperature and mass loss measurements of a bituminous coal during devolatilization, 1989. Combustion and Flame, 78, pp. 223-236.

12. Badzioch, S., and P. G. W. Hawksley. 1970. Kinetics of Thermal Decomposition of Pulverized Coal Particles, Ind. Eng. Chem., 9, 521.

13. Kobayashi, H., J. B. Howard, and A. F. Sarofim. Coal devolatilization at high temperatures, 1976. 16th Symposium (International) on Combustion, pp. 411-425. 
14. Hertzberg, M., I. A. Zlochower, and J. C. Edwards. Coal particle pyrolysis mechanisms and temperatures, 1988. Bureau of Mines Report of Investigations, United States Department of the Interior, Pittsburgh, Pennsylvania.

15. Hertzberg, M. and I. A. Zlochower. Devolatilization wave structures and temperatures for the pyrolysis of Polymethylmethacrylate, Ammonium Perchlorate, and Coal at combustion level heat fluxes, Combustion and Flame 84: 15-37 (1991).

16. Peters, W. and Bertling, H. Kinetics of the rapid degasification of coals, Fuel 44, p. 317 - 331, (1965).

17. Saxena, S. C. Devolatilization and combustion characteristics of coal particles, Prog. Energy Combust. Sci. 1990, Vol. 16, pp. 55-94.

18. Sampath, R. (1994), Measurement and Prediction of Temperature Histories for Single Coal Particles Prior to and During Devolatilization, Ph.D. Thesis, Department of Chemical Engineering, West Virginia University, Morgantown.

19. Sampath, R., Maloney, D. J., Zondlo, J. W., Woodruff, S. D., and Y. D. Yeboah, Measurements of Coal Particle Shape, Mass and Temperature Histories: Impact of Particle Irregularity on Temperature Predictions and Measurements, 26th Symposium (International) on Combustion/The Combustion Institute, Naples, Italy, July 1996.

20. Rosin, P. O., The influence of particle size in processes of fuel technology, Trans. Inst. Chem. Engrs., 15: 167 (1937).

21. Monazam, E. R. and D. J. Maloney, Characterization of mass and density distributions of sized coal fractions, Twenty-Fifth Symposium (International) on Combustion, 1994.

22. Maloney, D. J., Lawson, L. O., Fasching, G. E., and Monazam, E. R., A novel approach for determining external surface area and volume of irregularly shaped particles, Aerosol Sci. Technol. 22:60-72 (1995).

23. Maloney, D. J., Lawson, L. O., Fasching, G. E., and Monazam, E. R., Measurement and dynamic simulation of particle trajectories in an electrodynamic balance: characterization of particle drag coefficient/mass ratios, Rev. Sci. Instrum. 66:3615-3622 (1995).

24. Maloney, D. J., Monazam, E. R., Sampath, R., and Dodoo, J. N., An assessment of particle shape and thermal property data: implications for coal combustion modeling, 1990 Fall Technical meeting, Eastern Section of the Combustion Institute, December 3-5, Orlando, FL, Paper No. 91.

25. Merrick, D. 1983. Mathematical models of the thermal decomposition of coal, 2. Specific heats and heats of reaction, Fuel, 62, p. 540-546. 
26. Badzioch, S., D. R. Gregory, and M. A. Field. 1964. Investigation of the temperature variation of the thermal conductivity and thermal diffusivity of coal, Fuel, 43, 267.

27. Monazam, E. R. and D. J. Maloney, Temperature transients associated with pulsed heating of single particles, J. Appl. Phys. 71 (6), 1992.

28. Maloney, D. J., Monazam, E. R., and Sampath, R., Evaluation of errors resulting from particle shape assumptions applied in coal combustion modeling, Int. Conf. Coal Sci., Newcastle, UK, Sept. (1991).

29. Kirov, N. Y. 1965. Specific heats and total heat contents of coals and related materials at elevated temperatures, B.C.U.R.A. Monthly Bull., Review No. 241, p.33-57.

30. Van Krevelen, D. W. and Hoftyzer, P. J., Properties of Polymers, Elsevier Sci. Publishing Company, New York, 1976.

31. Singer, J. M., and R. P. Tye. 1979. Thermal, mechanical, and physical properties of selected bituminous coals and cokes, U.S. Bureau of Mines Report of Investigations No. 8364, pp. 37.

32. MacDonald, R. A., J. E. Callanan, and K. M. McDermott. 1987. Heat capacity of a mediumvolatile bituminous premium coal from 300 to $520 \mathrm{~K}$. Comparison with a high-volatile bituminous nonpremium coal, Energy and Fuel, 1, 535.

33. Badzioch, S. 1960. Thermo-physical properties of coals and cokes, B.C.U.R.A. Monthly Bull., 24, 485-520.

34. Kasperczyk, J. and Simonis, W., Gulkauf-Forschungshefte, 1971, vol. 32, pp. 23.

35. Agroskin, A. A., Goncharov, E. I. and Grayaznov, N. S., Coke and Chemistry (Eng. Trans.) 1972, vol. 9, pp. 3-5.

36. Monazam, E. R., D. J. Maloney, L. O. Lawson. 1989. Measurement of heat capacities, temperatures, and absorptivities of single particles, Rev. Sci. Instrum. 60, 3460.

37. Howard, J. B. 1981. Chemistry of Coal Utilization (M. A. Elliot, ed.) Second Supplementary Volume, p. 665-784, John Wiley \& Sons, New York.

38. Solomon, P. R., and D. G. Hamblen. 1985. Chemistry of Coal Conversion (R. H. Schlosberg, ed) pp. 121-251, Plenum Press.

39. Bliek, A., Poelje, W. M., Swaaij, W. P. M., and F. P. H. Beckum, Effects of intra-particle heat and mass transfer during devolatilization of a single coal particle, AIChE Journal (Vol. 31, No. 10), p.1666-1681, 1985. 
40. Tomeczek, J. and Kowol, J. Temperature field within a devolatilizing coal particle, The Canadian Journal of Chemical Engineering, vol 69, p. 286-293, (1991).

41. Ardent, P., and van Heek, K-H., Comparative Investigations of Coal Pyrolysis under Inert Gas and $\mathrm{H}_{2}$ at Low and High Heating Rates and Pressures up to 10MPa, Fuel 1981, Vol. 60, pp. 779.

42. Wagner, R., Wanzl, W., and van Heek, K-H., Influence of Transport Effects on Pyrolysis Reaction of Coal at High Heating Rates, Fuel 1985, Vol. 64, pp. 571.

43. Niksa, S., Heyd, L. E., Russel, W. B., and Saville, D. A., On the Role of Heating Rate in Rapid Coal Devolatilization, 20th Symposium (International) on Combustion, The Combustion Institute, Pittsburgh, Pennsylvania, 1984/pp. 1445-1453.

44. Yurum, Y., Karabakan, A. K., and Altuntas, N., Effect of Heating Rate on Glass Transition Temperature of Zonguldak Bituminous Coal, Energy \& Fuels 1991, 5, 701-703.

45. Juntgen, H., and van Heek, K-H., Gas Release from Coal as a Function of the Rate of Heating, Gordon Research Conference on Coal Science, New Hampshire, July 1967.

46. Sampath, R., Maloney, D. J., and Zondlo, J. W., Measurements of Surface Area and Volume for Irregularly-Shaped Coal Particles, Central States Technical Meeting, Combustion Institute, 31 May - 2 June, 1998, Lexington, KY.

47. Maloney, D. J., Sampath, R., and Zondlo, J. W., Heat Capacity and Thermal Conductivity Considerations for Coal Particles During the Early Stages of Rapid Heating, Combustion and Flame 116:94-104 (1999).

48. Sampath, R., Maloney, D. J., and Zondlo, J. W., Evaluation of Thermophysical and Thermochemical Heat Requirements for Coals at Combustion Level Heat Fluxes, 27th International Symposium on Combustion, August 2-7, 1998, Boulder, CO.

49. Sampath, R., Maloney, D. J., and Proscia, W., Thermal Property Data for Coal Particles for Use in Rapid Devolatilization Models, Technology Transfer Session, Historically Black Colleges/Universities and Other Minority Institutions Annual Symposium, April 28-29, 1998, Ocean City, MD.

50. Taylor, J., Sampath, R., Maloney, D. J., and Proscia, W., Rapid Devolatilization Studies for Coal Particles in an Electrodynamic Balance and in a Heated Grid Reactor, Technology Transfer Session, Historically Black Colleges/Universities and Other Minority Institutions Annual Symposium, April 28-29, 1998, Ocean City, MD. 